\title{
Varicocele Secondary to Spermatic Cord Hematoma Related to Blunt Trauma
}

\author{
Yeon Won Park, Jun Ho Lee ${ }^{1}$ \\ Department of Urology, National Police Hospital, ${ }^{I}$ Department of Urology, Nowon Eulji Medical Center, Eulji University, Seoul, Korea
}

\begin{abstract}
A secondary varicocele caused by spermatic cord hematoma has not been reported. This paper presents a 17-year-old patient with varicocele secondary to spermatic cord hematoma related to blunt trauma. Ultrasonography immediately after the injury revealed a hematoma surrounding the spermatic vessels at the level of the left inguinal area where he had been kicked. Distal to the spermatic cord hematoma, the spermatic vessels began to dilate, and their maximum resting diameter was up to $8 \mathrm{~mm}$. Six-months after the injury, ultrasonography still showed a varicocele, and the testosterone level was below the normal range. After a varicocelectomy, ultrasonography revealed a significant decrease in the size of the spermatic vessels, and the testosterone level returned to normal. This case suggests that a varicocele due to trauma might not be a self-limiting disease and can be treated by a varicocelectomy and hematoma removal.
\end{abstract}

Keywords: Varicocele; Spermatic cord; Hematoma; Trauma; Testosterone

Copyright $\subset$ c) 2020, Korean Association of Urogenital Tract Infection and Inflammation. All rights reserved. (c) (1) (s) This is an open access article distributed under the terms of the Creative Commons Attribution Non-Commercial License (http://creativecommons.org/licenses/by-nc/4.0) which permits unrestricted non-commercial use, distribution, and reproduction in any medium, provided the original work is properly cited.
Received: 10 July, 2020

Revised: 9 October, 2020

Accepted: 30 November, 2020

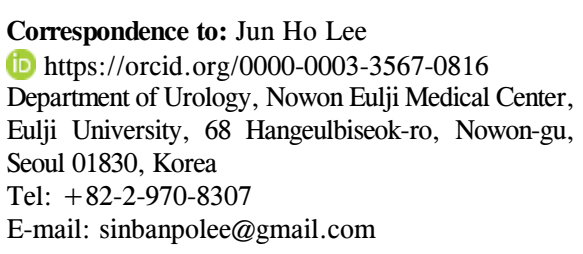

Spermatic cord hematoma due to blunt trauma is a very rare disease [1]. A secondary varicocele caused by a spermatic cord hematoma has not been reported; the present patient is the first reported case. This paper reports a unique case study with an unusual etiology.

\section{CASE REPORT}

A 17-year-old boy presented to the emergency department with acute swelling and discomfort of the left scrotum. The patient noticed mild ecchymosis and swelling in the left inguinal area. The swelling developed two hours before visiting the clinic after being kicked in his inguinal area by his classmate. He denied any history of a previous varicocele, coagulation disorders, or comorbidities. The physical examination revealed a grade III varicocele on his left scrotum, which means that the distended venous plexus bulged visibly through the scrotal skin and was easily palpable.

Ultrasonography revealed a hematoma surrounding the spermatic vessels at the level of the left inguinal area where he had been kicked, and no active bleeding was observed (Fig. 1). Distal to the spermatic cord hematoma, the spermatic vessels had begun to dilate, and their maximum resting diameter was up to $8 \mathrm{~mm}$ (Fig. 2) in the upper scrotum. Reflux flow in the pampiniform plexus of the veins was observed on color-flow Doppler ultrasonography. Both testes had a normal structure and blood flow. Contrast-enhanced computed tomography was performed owing to the rarity of the condition. The images revealed thickening of the left spermatic cord with heterogeneous enhancement inside the cord (Fig. 3). No evidence of injury to any other site was noted. The patient was diagnosed with a grade III varicocele induced by a spermatic cord hematoma associated with blunt trauma.

Initially, the patient was treated conservatively with bed 


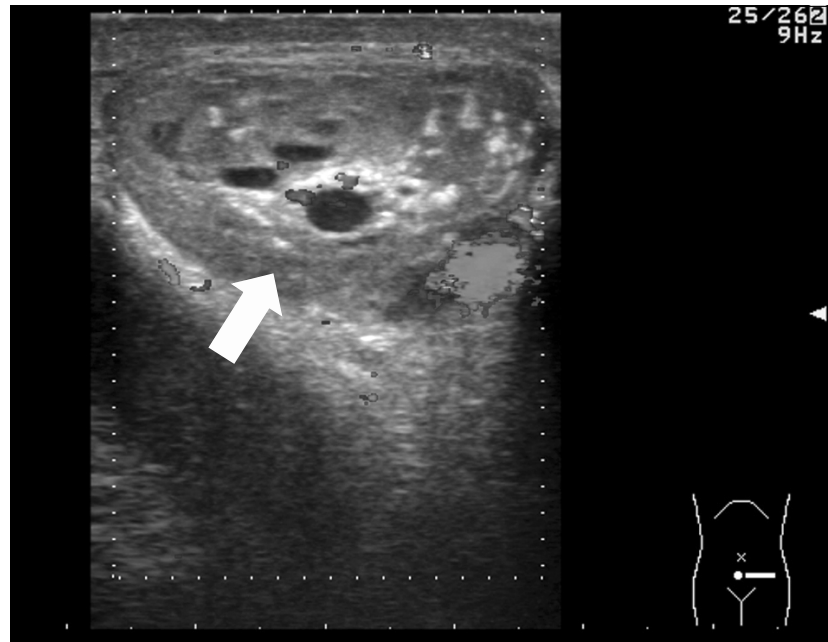

Fig. 1. Ultrasonography immediately after injury revealed a hematoma (arrow) of the spermatic cord.

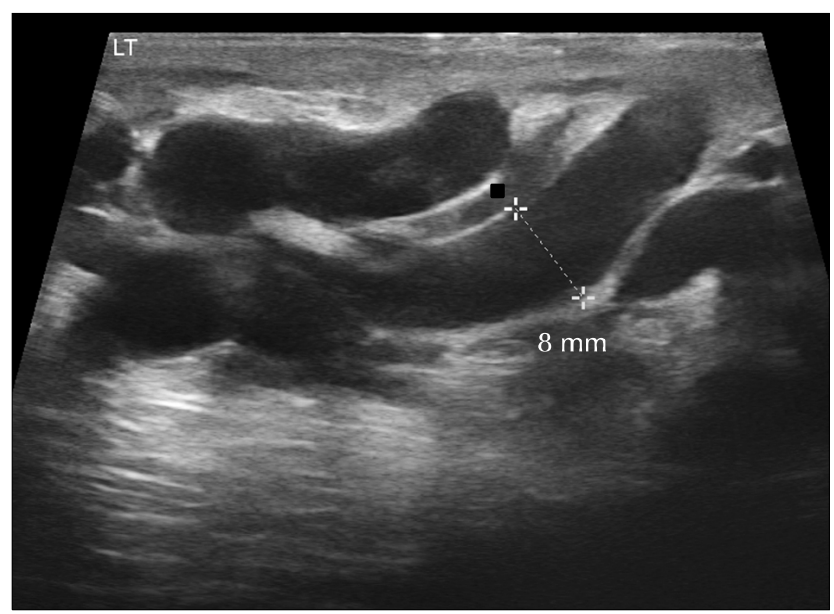

Fig. 2. Ultrasonography showed that the diameter was large before treatment with a maximum resting diameter of $8 \mathrm{~mm}$.

rest, ice packs, antibiotics, and analgesics. During hospitalization, he was stable, the discomfort decreased gradually, and the patient was discharged on the third day. After discharge, serial ultrasonography was performed, which revealed a decrease in the size of the spermatic vessels. On the other hand, follow-up ultrasonography performed at six months still showed a varicocele with a maximal resting diameter of $6 \mathrm{~mm}$. The estimated sizes of the left and right testes were $10 \mathrm{ml}$ and $12 \mathrm{ml}$, respectively. In addition, the testosterone level three months postinjury was below the normal range $(3.02 \mathrm{ng} / \mathrm{ml})$, and the testosterone level six months postinjury had not increased significantly $(3.36$ $\mathrm{ng} / \mathrm{ml}$ ). Six months postinjury, a left microscopic varicocelectomy was carried out. An incision was made at the level

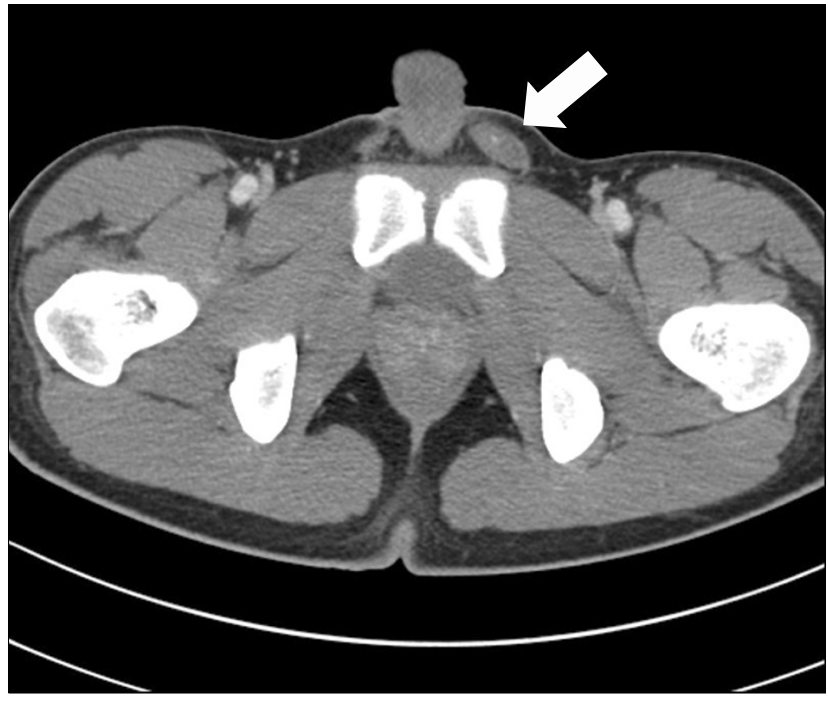

Fig. 3. Contrast-enhanced computed tomography at the level of the left inguinal area where the patient was kicked revealed thickening of the left spermatic cord, demonstrating heterogeneous enhancement inside the cord (arrow).

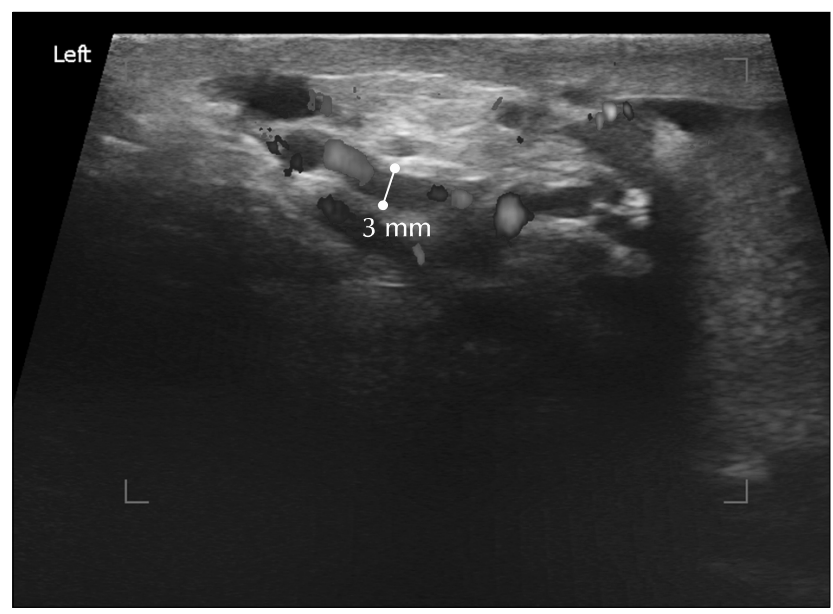

Fig. 4. Ultrasonography showed that the maximum resting diameter of the spermatic vein had decreased to $3 \mathrm{~mm}$.

of the hematoma (inguinal area), four dilated spermatic vessels were ligated, and the hematoma surrounding the spermatic vessels located just beneath the cremasteric muscle was removed completely. Three months after surgery, there was no visible varicocele, and ultrasonography showed a significant decrease in the size of the spermatic vessels (maximal resting diameter of $3 \mathrm{~mm}$ ) (Fig. 4). Eleven months after surgery, the testosterone level returned to normal (5.06 $\mathrm{ng} / \mathrm{ml})$; the estimated sizes of the left and right testes were $12 \mathrm{ml}$ and $12 \mathrm{ml}$, respectively. 


\section{DISCUSSION}

Blunt spermatic cord hematoma is extremely rare [1]. Limited data are available, and only four cases of such injuries have been reported thus far [1-4]. A possible etiology for spermatic cord hematoma would be a tear or rupture of the cremasteric vessels, spermatic vessels, or varicocele. In the present case, the patient denied any prior history of scrotal swelling, mass, or varicocele. No injury or adhesion of the spermatic vessels was observed, and the spermatic vessels were separated easily as usual during varicocelectomy. Therefore, the spermatic cord hematoma, in this case, was induced by the injury to the cremasteric vessels related to blunt trauma.

A varicocele is defined as a vascular lesion characterized by tortuosity and dilatation of the spermatic veins $[5,6]$. Varicoceles can be primary, which means that absent or defective valves in the spermatic vein, which help prevent the retrograde flow of blood, cause an increase in pressure within the spermatic veins and subsequent varicocele formation. Secondary varicoceles can occur due to direct or indirect compression of the venous drainage of the testis by extraspermatic lesions, such as pelvic or abdominal masses. Renal carcinoma (caused by obstruction of the renal vein by the tumor), retroperitoneal tumors, retroperitoneal fibrosis, and liver cirrhosis (caused by portal hypertension) are possible causes of a secondary varicocele [5,6]. Trauma would be another etiology of secondary varicoceles, considering a previous case of varicocele due to post-traumatic arteriovenous fistula [7].

In the present case, the varicocele may have occurred due to direct compression of the spermatic cord hematoma on the spermatic vein. This is interesting because all reported cases of spermatic cord hematoma have been associated with scrotal hematoma. Moreover, to the best of the authors' knowledge, there are no reports on spermatic cord hematoma related to a varicocele. The present case is the first report describing a secondary varicocele induced by blunt trauma to the inguinal area. On the other hand, varicocele rupture due to blunt trauma or sexual intercourse has been reported [3,8].

The patient did not notice his varicocele because a varicocele could present without symptoms and are found incidentally on a physical examination [9]. Therefore, the possible presence of the varicocele before blunt trauma could not be excluded, even though he denied any history of a previous varicocele, and the spermatic vessels distal to the spermatic cord hematoma began to dilate on ultrasonography.

Adolescent varicoceles can induce a reduction in testicular volume and the regression of testicular development [10-12]. Furthermore, untreated varicoceles might result in androgen deficiency even in younger men [13]. Several studies have shown that varicocele repair results in testicular growth and an increase in the serum testosterone level [13]. Therefore, early varicocele repair in adolescent patients with varicoceles combined with low testosterone levels or discrepancies in the testis size should be considered promptly in current management practices [14]. In the present case, it was believed that the varicocele would disappear after the hematoma of the spermatic cord had been resolved. On the other hand, the varicocele persisted for six months postinjury, and low testosterone levels and discrepancies in testicular size (albeit not significant) were observed. This is an interesting finding, which suggests that a varicocele related to a spermatic cord hematoma due to blunt trauma would not be a self-limiting disease and could be treated by a varicocelectomy and hematoma removal. Consequently, a varicocelectomy was performed, and the testosterone level returned to normal.

A varicocele might result in a dysfunction of the Leydig cells and lead to decreased testosterone production. In this case, a grade III varicocele was still noted even at six months post-injury. Therefore, a grade III varicocele induced by spermatic cord hematoma caused a decrease in serum testosterone level at three and six months post-injury.

In summary, this is the first report of a case of a varicocele related to spermatic cord hematoma due to blunt inguinal trauma. This case suggests that a varicocele due to trauma might not be a self-limiting disease and can be treated by a varicocelectomy and hematoma removal. Further experience will be needed for the treatment of varicoceles related to trauma.

\section{CONFLICT OF INTEREST}

No potential conflict of interest relevant to this article was reported. 


\section{AUTHOR CONTRIBUTIONS}

Y.W.P. and J.H.L. participated in data collection and wrote the manuscript. Y.W.P. and J.H.L. participated in the study design and performed the statistical analysis. Y.W.P. and J.H.L. participated in the study design and coordination and helped to draft the manuscript. All authors read and approved the final manuscript.

\section{ORCID}

Yeon Won Park, https://orcid.org/0000-0003-0751-8892 Jun Ho Lee, https://orcid.org/0000-0003-3567-0816

\section{REFERENCES}

1. Takasu A, Morita K, Kaneko N, Sakamoto T, Okada Y. Spermatic cord injury associated with blunt trauma. Am J Emerg Med 2005;23:806-7.

2. Rabkin RN, Amar AD. Traumatic false aneurysm of the spermatic artery: a case report. J Urol 1968;100:50-1.

3. Gordon JN, Aldoroty RA, Stone NN. A spermatic cord hematoma secondary to varicocele rupture from blunt abdominal trauma: a case report and review. J Urol 1993;149:602-3.

4. Kumar S, Rao MS, Sharma SK, Raghu K, Datta BN. Traumatic organized hematoma of the spermatic cord. J Urol 1981;126: 275-6.
5. Mohammed A, Chinegwundoh F. Testicular varicocele: an overview. Urol Int 2009;82:373-9.

6. Raheem OA. Surgical management of adolescent varicocele: systematic review of the world literature. Urol Ann 2013;5: 133-9.

7. Petrocelli F, Bovio G, Utili A, Camisassi N. Varicocele due to post-traumatic arteriovenous fistula. Urology 2018;115:e1-2.

8. Nishiyama $Y$, Nagai A, Nasu $Y$, Watanabe $M$, Kusumi $N$, Monden $\mathrm{K}$, et al. Varicocele rupture due to sexual intercourse. Int J Urol 2005;12:585-7.

9. Polackwich AS, Sabanegh E Jr. Asymptomatic postpubertal male with equally sized normal testicles with palpable left varicocele. Asian J Androl 2016;18:310.

10. Laven JS, Haans LC, Mali WP, te Velde ER, Wensing CJ, Eimers JM. Effects of varicocele treatment in adolescents: a randomized study. Fertil Steril 1992;58:756-62.

11. Paduch DA, Niedzielski J. Repair versus observation in adolescent varicocele: a prospective study. J Urol 1997;158(3 Pt 2):1128-32.

12. Cayan S, Akbay E, Bozlu M, Doruk E, Erdem E, Acar D, et al. The effect of varicocele repair on testicular volume in children and adolescents with varicocele. J Urol 2002;168:731-4.

13. Sathya Srini V, Belur Veerachari S. Does varicocelectomy improve gonadal function in men with hypogonadism and infertility? Analysis of a prospective study. Int J Endocrinol 2011;2011:916380.

14. Chung JM, Lee SD. Current issues in adolescent varicocele: pediatric urological perspectives. World J Mens Health 2018; 36:123-31. 